\title{
Numerical Simulations of Dynamic Behavior of Polyurea Toughened Steel Plates under Impact Loading
}

\author{
Chien-Chung Chen ${ }^{1}$ and Daniel G. Linzell ${ }^{2}$ \\ ${ }^{1}$ Department of Mechanical Engineering, Purdue University Calumet, Hammond, IN 46323, USA \\ ${ }^{2}$ Department of Civil Engineering, University of Nebraska-Lincoln, Lincoln, NE 68588, USA \\ Correspondence should be addressed to Chien-Chung Chen; chien-chung.chen@purduecal.edu
}

Received 29 September 2014; Revised 9 December 2014; Accepted 11 December 2014; Published 29 December 2014

Academic Editor: George Labeas

Copyright (c) 2014 C.-C. Chen and D. G. Linzell. This is an open access article distributed under the Creative Commons Attribution License, which permits unrestricted use, distribution, and reproduction in any medium, provided the original work is properly cited.

\begin{abstract}
The objective of the work discussed herein is to develop a nonlinear 3D finite element model to simulate dynamic behavior of polyurea toughened steel plates under impact loading. Experimental and numerical work related to model development are presented. Material properties are incorporated into numerical models to account for strain-rate effects on the dynamic behavior of polyurea and steel. One bare steel plate and four polyurea toughened steel plates were tested under impact loading using a pendulum impact device. Displacement time-history data from experimental work was used to validate the numerical models. Details on material model construction, finite element model development, and model validation are presented and discussed. Results indicate that the developed numerical models can reasonably predict dynamic response of polyurea toughened steel plates under impact loading.
\end{abstract}

\section{Introduction}

Extreme natural and man-made hazards have always posed threats to civil infrastructure. Typical natural threats include earthquakes and hurricanes and man-made hazards can include malicious events caused by explosions or vehicle collisions. As conventional structures designed primarily based on strength and serviceability criteria can, in some instances, be vulnerable to impulsive and impact loads, it was of interest to examine new structural systems and materials that might better protect important structural components against these loads. This paper summarizes portions of a study that investigated the effectiveness with which an innovative coating material helped improve steel structural component impact resistance.

Polyurea is a coating material that has received research interest due to its effective energy absorption properties. Davidson et al. [1] utilized polyurea as a blast load retrofitting material for masonry wall systems in residential or low-rise office structures. Fatt Hoo et al. [2] investigated the performance of polyurea strengthened concrete masonry walls subjected to blast loading. Results suggested that polyurea coated concrete masonry walls could improve blast resistance and reduce fragmentation. Also, Porter et al. [3] indicated that polyurea can be used to increase blast resistance of timber-framed structures. Nevertheless, the performance of various substrate materials coated with polyurea, from brittle materials like the aforementioned concrete and masonry to more ductile materials like steel, may vary widely because of the inherent different material behavior between brittle and ductile materials, and, as a result, approaches for using polyurea to strengthen structural components made of these materials differ. The research outlined herein examined application of polyurea onto steel structures.

Metals, like many materials, behave differently under dynamic loading conditions that cause high strain rates, such as an impact event, when compared to static loads. Under dynamic conditions, steels may experience strain rates that can change their response from ductile to brittle. The ultimate tensile strength of steels under high strain-rate loading is also known to be higher than that of steels under static loading conditions (Meyers [4]). Predicting the high strain-rate behavior of metallic material has been studied for some time. Johnson and Cook [5] conducted experimental 
work and developed an empirically based material model to address this behavior. This material model has been widely used by researchers [6-9] to predict response of metals under impact.

Ward and Hadley [10] mentioned that the mechanical properties of polymers are also dependent on strain rate and temperature. Like steels, polymers can also possess increased strength under a high strain rate or at low temperature. Yi et al. [11] experimentally investigated strain-rate effects on the stress-strain behavior of polyurea and polyurethanes using quasi-static compression testing and compressive split Hopkinson pressure bar (SHPB) testing. Strain rates that were investigated ranged from $10^{-3} \mathrm{~s}^{-1}$ to $10,000 \mathrm{~s}^{-1}$. Results showed that polyurea exhibited cyclic softening behavior and strong rate dependence. Furthermore, there was a transition from rubbery behavior at lower strain rates to glassy behavior at higher strain rates. More recently, Shim and Mohr [12] performed compression tests on polyurea at strain rates ranging from $10^{-1} \mathrm{~s}^{-1}$ to $1,200 \mathrm{~s}^{-1}$ using a modified SHPB device. Measured compressive behavior (stress-strain curves) was similar to that observed by Yi et al. [11]. In another experimental study by Roland et al. [13], polyurea coupon specimens were tested to failure in tension at strain rates ranging from $0.06 \mathrm{~s}^{-1}$ to $573 \mathrm{~s}^{-1}$ using a drop weight testing device. Results from this study showed the stiffness of polyurea notably increasing with increased strain rates. It was also noted that there was a distinction between the tension and compression behavior of polyurea. The transition from rubbery to glassy behavior described by Yi et al. [11] was not observed from the tension tests (Roland et al. [13]). Owing to the complex behavior of polyurea at varying strain rates, modeling its behavior is still a challenge.

As presented above, researchers have investigated the behavior of both steel and polyurea under varying strain rates. Nevertheless, public domain research that has examined the performance of polyurea/steel composite structures subjected to impact loading is limited. It was of interest to study how a steel and polyurea composite system performs under higher strain rates resulting from an impact. While past studies [6-9] focused on numerical simulations of local penetrations of metal plates without polyurea coating, the work presented herein attempted to develop a numerical model capable of predicting the dynamic behavior of polyurea toughened steel structures under impact loading. Specifically, quantitative comparisons of the dynamic behavior of polyurea toughened steel plates under impact loading obtained from both experimental and numerical studies were made. The next section describes the experimental program, followed by finite element model development and model validation.

\section{Experimental Program}

A total of five tests were conducted using a pendulum impact device. Results from the tests were utilized to examine impact behavior of polyurea toughened steel plates and to verify the applicability of developed numerical models to evaluate
TABle 1: Dimensions of impact test specimens.

\begin{tabular}{lccccc}
\hline & S1 (bare steel) & SPF1 & SPB1 & SPF2 & SPB2 \\
\hline Width $(\mathrm{mm})$ & 762 & 762 & 762 & 762 & 762 \\
Length $(\mathrm{mm})$ & 762 & 762 & 762 & 762 & 762 \\
Steel thickness $(\mathrm{mm})$ & 6.35 & 6.35 & 6.35 & 6.35 & 6.35 \\
Polyurea thickness $(\mathrm{mm})$ & 0.00 & 19.6 & 15.7 & 15.7 & 20.4 \\
\hline
\end{tabular}

nonlinear dynamic behavior of polyurea and steel composite structures under impact loading.

2.1. Materials. Polyurea, the coating material used to toughen steel in this study, results from a chemical reaction of an isocyanate and an amine. It is conventionally used to protect structures, such as steel bridges, tanks, and chemical plants, against corrosion and abrasion. Recently, the excellent energy absorption properties of polyurea have drawn the interest of researchers interested in improving the blast/impact resistance of various materials and structures.

AISI 4340 steel was used as the substrate investigated in this work. AISI 4340 steel is generally used for aircrafts, automobiles, and structural parts. Conducted tests examined impact response of polyurea toughened AISI 4340 steel plates under high strain-rate loading.

2.2. Specimen Preparation. Impact test specimens consisted of one bare steel plate and four polyurea coated steel plates. The test plates were cut from AISI 4340 steel plates with dimensions of $1651 \mathrm{~mm} \times 1651 \mathrm{~mm} \times 6.35 \mathrm{~mm}$ (width $\times$ length $\times$ thickness). The plate cutting process was performed using a water-jet cutting machine to avoid generating excessive heat. To prepare polyurea coated specimens, the steel plates were coated using a pour on polyurea compound that cured at room temperature. Dimensions of the test specimens are listed in Table 1. Specimen S1 was a bare steel plate and the other specimens were polyurea coated steel plates. Specimens SPF1 and SPF2 were tested with the polyurea facing the impact, and Specimens SPB1 and SPB2 were tested with the steel facing the impact. As indicated in the table, polyurea thicknesses differed slightly between coated specimens.

2.3. Test Setup and Procedure. A schematic of the pendulum test setup is shown in Figure 1. The test frame was anchored to a strong floor and had an impactor with a mass of $136 \mathrm{~kg}$ and a swing radius of $2.09 \mathrm{~m}$. The tip of the steel impactor was hemispherical with a diameter of $25.4 \mathrm{~mm}$. Test specimens were bolted at their corners to two steel beams. Nonlinear dynamic behavior was achieved by dropping the pendulum impactor from a height of $2.09 \mathrm{~m}$.

Two high speed cameras were used to capture specimen deformations when impacted by the pendulum. The cameras were set to record 1,000 frames per second with a total filming duration of 2 seconds. Pictures taken by the high speed cameras were used to estimate plate deflections for comparisons against results from numerical simulations. Camera positions are shown in Figure 2. 


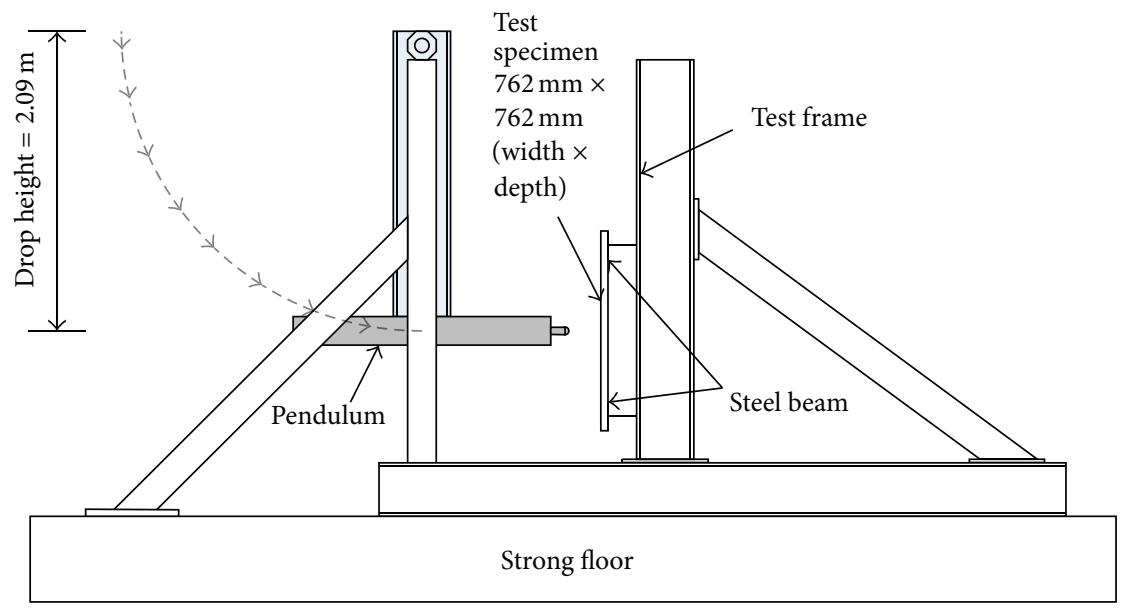

FIGURE 1: Impact pendulum test frame.

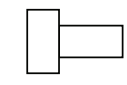

High speed camera 1

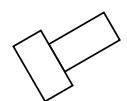

High speed camera 2
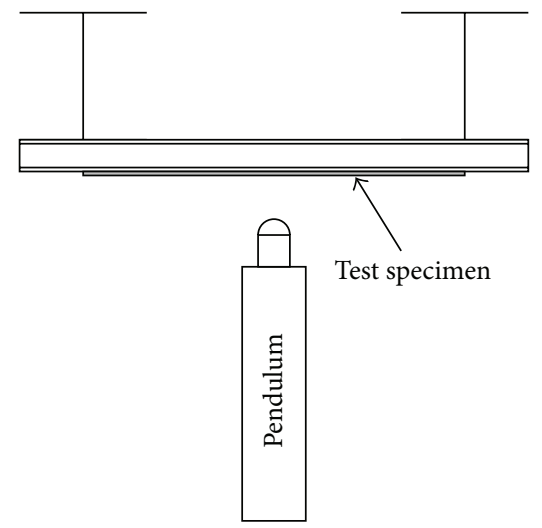

Test specimen

FIGURE 2: Plan view of high speed camera locations.
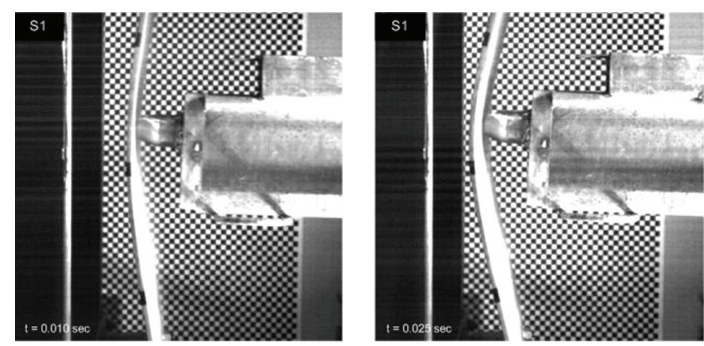

FIGURE 3: Representative photos from the impact test.

2.4. Results. Figure 3 shows two representative photos taken from Specimen S1 (bare steel) at 0.010 and 0.025 seconds, respectively, after initial contact. The observed peak deflection occurred at approximately 0.025 seconds. The plate also experienced slight torsion due to some load eccentricities. Similar responses were observed from other coated specimens.

Deflections comprising local indentations at the impact point and global deformations at the location of the impact were estimated by scaling dimensions in the pictures to actual

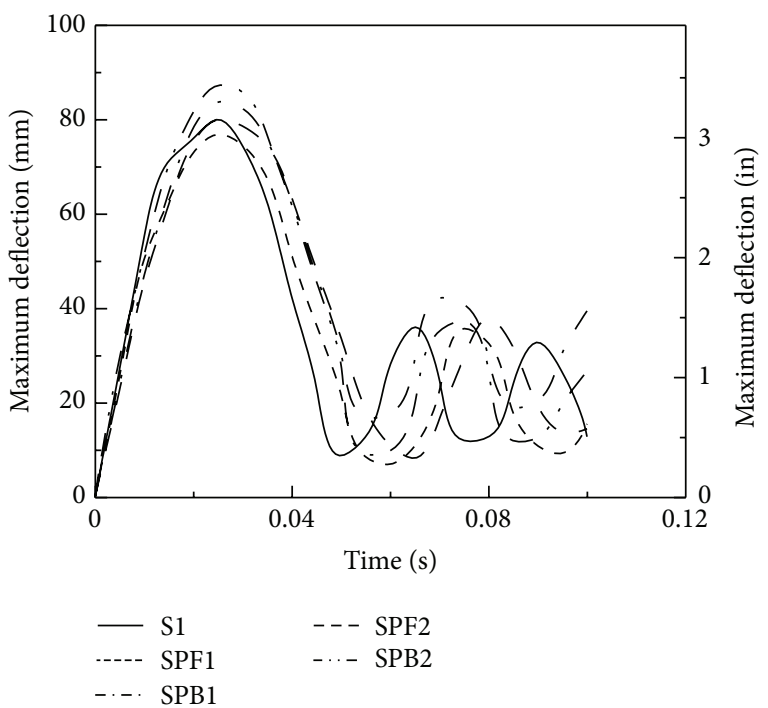

Figure 4: Deflection time-histories from the impact tests.

displacements. Figure 4 shows the resulting deflection timehistories from the impact tests. Nonlinear dynamic responses were clearly observed in all specimens. During impact no debonding between polyurea and steel was observed.

As shown in Figure 4, deflections of the coated plates were comparable with that of the bare steel plate. This result suggested that, as expected, polyurea coating was not effective at increasing plate stiffness.

\section{Numerical Program}

As previously mentioned, studies on dynamic behavior of polyurea coated metal structures under high strain-rate loading are limited. Furthermore, quantitative comparisons between impact tests and numerical simulations were seldom completed in past studies. Therefore, it was of interest to develop a numerical model to simulate dynamic responses 
TABLE 2: AISI 4340 steel material constants.

\begin{tabular}{lccc}
\hline$A(\mathrm{MPa})$ & $B(\mathrm{MPa})$ & $C$ & $n$ \\
\hline 489.5 & 500.7 & 0.014 & 0.26 \\
\hline
\end{tabular}

of polyurea toughened steel members under high strainrate loading and to make quantitative comparisons against impact test data. Numerical models of impact tests summarized in the previous section were created and validated against experimental results. The numerical study was carried out utilizing LS-DYNA [14], a commercially available finite element analysis software package.

3.1. Material Models. The Johnson-Cook material model (Johnson and Cook [5]) is a strain-rate-dependent, empirical material model that has been widely used to simulate the behavior of metallic materials when rate effects are prominent. Johnson-Cook material constants for AISI 4340 steel were first reported by Johnson and Cook [15]. Later, the material model was used by other researchers [16-18] to simulate AISI 4340 steel under high strain-rate conditions, showing a good correlation between numerical and experimental results. For this reason, the Johnson-Cook model was selected as the material model for the AISI 4340 steel in this study. The expression for stress from the Johnson-Cook material model is as follows:

$$
\sigma=\left[A+B\left(\varepsilon^{\mathrm{pl}}\right)^{n}\right]\left[1+C \ln \left(\dot{\varepsilon}^{*}\right)\right]\left[1-T^{* m}\right],
$$

where $\varepsilon^{\mathrm{pl}}$ is the effective plastic strain, $\dot{\varepsilon}^{*}$ is the normalized effective plastic strain rate, and $T^{*}$ is the dimensionless temperature parameter.

Because thermal effects were not considered in this study, a simplified form of the Johnson-Cook material model (LSTC [19]) was utilized:

$$
\sigma=\left[A+B\left(\varepsilon^{\mathrm{pl}}\right)^{n}\right]\left[1+C \ln \left(\dot{\varepsilon}^{*}\right)\right],
$$

where $A, B, C$, and $n$ are required empirical constants, similar to those presented in the original model. Empirical constants $C$ and $n$ were consistently reported from previous studies [1518 ] to be 0.014 and 0.26 , respectively, and were adopted for the current study. $A$ and $B$ were obtained utilizing quasi-static tension test data reported by Chen [20] and were selected by curve fitting equation (2) to true stress-effective plastic strain curves from these tension tests using the least squares method. The obtained constants for $A$ and $B$ were $489.5 \mathrm{MPa}$ and $500.7 \mathrm{MPa}$, respectively.

Material constants used for the AISI 4340 steel are tabulated in Table 2.

Developed polyurea constitutive models have been largely empirically based, requiring a large amount of experimentally derived input. The material model selected for polyurea in this study was an elastoplastic representation (Material Type 112, MAT_FINITE_ELASTIC_STRAIN_PLASTICITY, LSTC [19]) that incorporated test data to define hardening behavior for a wide range of strain rates. High strain-rate tensile properties from Roland et al. [13] were

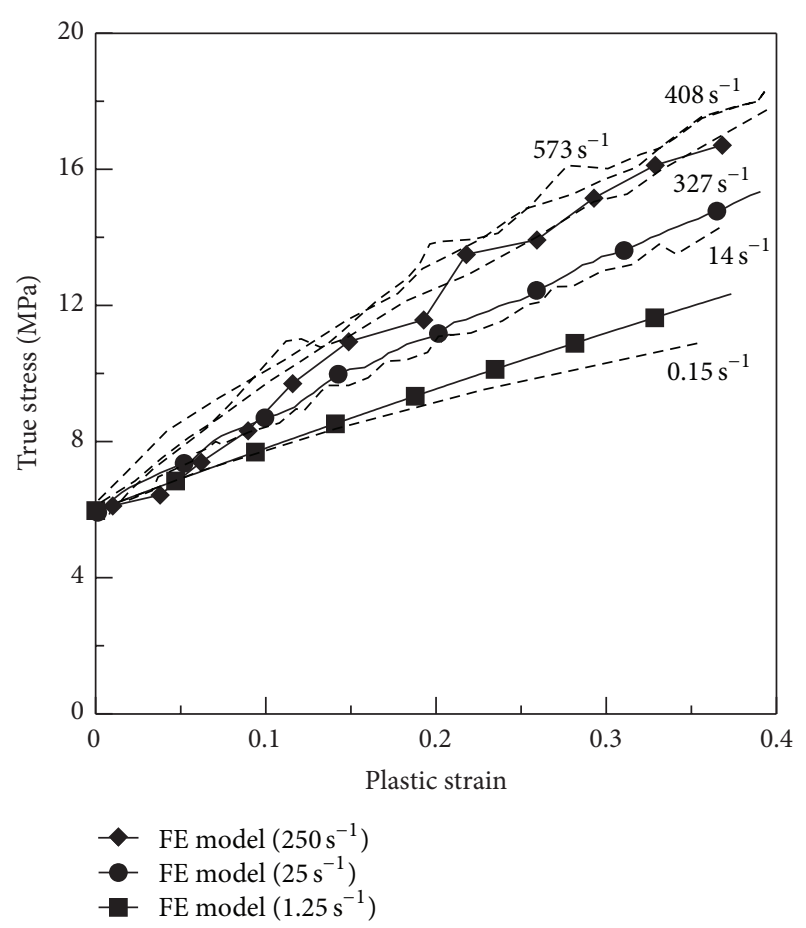

FIGURE 5: True stress versus effective plastic strain.

utilized to construct the material model for polyurea to account for strain-rate effects. Roland et al. conducted tension tests on polyurea at rates ranging between $0.15 \mathrm{~s}^{-1}$ and $573 \mathrm{~s}^{-1}$. This tension test data was first converted to true stress versus plastic strain data (dashed lines in Figure 5) and this data was then incorporated into the material model to represent polyurea's rate dependent properties. To validate the strain-rate sensitivity of the material model, three tension test numerical models having average strain rates ranging from $1.25 \mathrm{~s}^{-1}$ to $250 \mathrm{~s}^{-1}$ were created and compared against experimental data. As shown in Figure 5, material model rate dependent behavior was demonstrated and was comparable to reported tension test results [13]. The yield stress and Young's modulus were estimated using the measured elastic limit and the slope of the material's response to its observed proportional limit. The approximated yield stress and Young's modulus were $5.9 \mathrm{MPa}$ and $71.1 \mathrm{MPa}$, respectively. Poisson's ratio was assumed to be 0.45 to represent incompressible behavior observed for polyurea.

3.2. Impact Test Model. Finite element models of the impact test specimens were created using the LS-DYNA finite element software package [14]. The models were created to represent actual dimensions and support conditions used for the impact test setup outlined in the previous section. Eightnode brick elements with one integration point were used for both the steel and the polyurea, with the dimensions of a single element being $25.4 \mathrm{~mm} \times 25.4 \mathrm{~mm}$ and with the thickness of each element being one-tenth of the steel/polyurea thickness. Since no debonding was observed from the impact tests, the polyurea and steel were assumed to be perfectly 


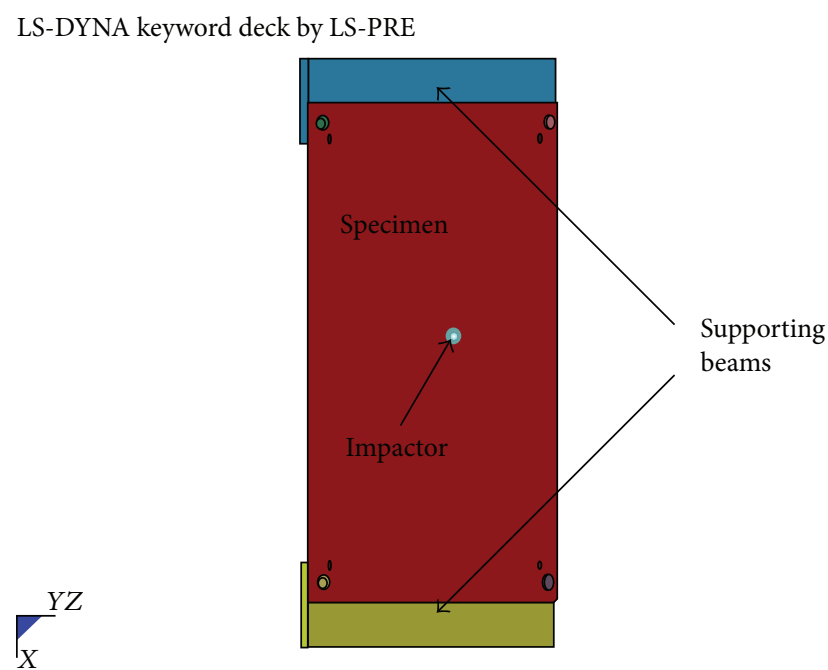

FIGURE 6: Finite element model of the impact test setup.

bonded. Figure 6 shows the resulting finite element model of the impact tests. Impact force was induced via a spherical object with a mass equivalent to the mass of the pendulum. To keep the contact area in the simulations consistent with that in the tests, the spherical impactor had a diameter that matched the diameter of the hemispherical tip of the impact pendulum and the contact location was defined at the impact point used for the tests.

Deformations experienced by the impactor and supporting beams were assumed to be negligible when compared to deformations experienced by the plate specimens and, as a result, they were assumed to be rigid in the finite element models.

Support conditions created in the finite element models were identical to those used for the impact tests, with specimens being bolted at their corners to supporting beams. Bolted joints were explicitly created in the models to mimic test support conditions and, as a result, the plates were largely fixed in place. The effects of clamping force and friction were not taken into account in the finite element analyses.

In the finite element simulations, "contact" properties need to be defined when one or more parts in the model may come in contact during loading to prevent unrealistic penetrations of one component into another. For the impact test simulation in the current study, bodies that may come in contact included the impactor and plate, the plate and supports, and the plate and bolts. Therefore, contact properties between these parts need to be addressed and were defined in the impact test models using the LS-DYNA contact function, ${ }^{*}$ CONTACT_AUTOMATIC_SURFACE_TO_SURFACE. This contact approach defines a slave surface and a master surface that may come in contact and during the analysis slave and master nodes were checked for penetration through each other. The master/slave surface provided additional boundary constraints that would force penetrating nodes back to the surface once penetration was detected.
TABLE 3: Maximum and permanent deflection comparisons.

\begin{tabular}{lcccc}
\hline \multirow{2}{*}{ Specimen } & \multicolumn{2}{c}{ Max. deflections (mm) } & \multicolumn{2}{c}{ Plastic deflections (mm) } \\
& Experiment & FEM & Experiment & FEM \\
\hline S1 & 80.0 & 78.4 & 22.4 & 48.9 \\
SPF1 & 76.8 & 72.8 & 21.3 & 34.1 \\
SPB1 & 83.7 & 83.0 & 29.6 & 43.8 \\
SPF2 & 80.0 & 75.1 & 23.1 & 41.4 \\
SPB2 & 87.2 & 81.5 & 23.2 & 41.5 \\
\hline
\end{tabular}

To simulate the impact, an impact velocity was determined by converting impactor potential energy to kinetic energy from actual tests. Using known values for the mass of the pendulum $(136 \mathrm{~kg})$, the drop height $(2.09 \mathrm{~m})$, and the acceleration due to gravity, this impact velocity, $v$, was determined to be $6.4 \mathrm{~m} / \mathrm{s}$.

Analyses were terminated $0.1 \mathrm{sec}$ after an initial contact so displacement time-histories from the finite element analyses would be comparable to those from impact tests. Maximum displacements were identified and the permanent deflections (plastic deflections) were also found. These values were used to validate the finite element models.

3.3. Results and Discussions. Figure 7 shows quantitative comparisons of displacement time-histories between numerical and experimental results while Table 3 compares maximum and plastic deflections. Specimen plastic deflections were measured after the impact tests. From the test data, it was observed that the plastic deformations could be reasonably estimated by averaging deflections between the second peak and the lowest point between the first and second peaks. Therefore, the average deflection method was used to approximate plastic deflections of the finite element models in order to reduce computation time.

As shown in Figure 7, displacement time-histories from the analyses, particularly the peak deflections, agreed well with experimental results. The difference between predicted peak deflections and maximum deflections obtained from the impact tests was less than $7 \%$. It should be noted that in many structural engineering applications accurate predictions of maximum deformations, those that commonly occur at the first peak, are typically what is desired. In addition, initial slopes of the displacement time-histories were comparable between the analyses and experiments. This demonstrated that the plate stiffness in the finite element models was similar to that of test specimens. Although the finite element models presented good agreement for peak deflections and plate stiffness, plastic deflections of the plates after impact were overestimated by the models by between $48 \%$ and $118 \%$ with the plastic deflection experienced by Specimen S1 (bare steel) being overpredicted by $118 \%$. More impact tests would be needed to better improve material constants used in the selected constitutive models if predictions of postpeak behavior are desired. 

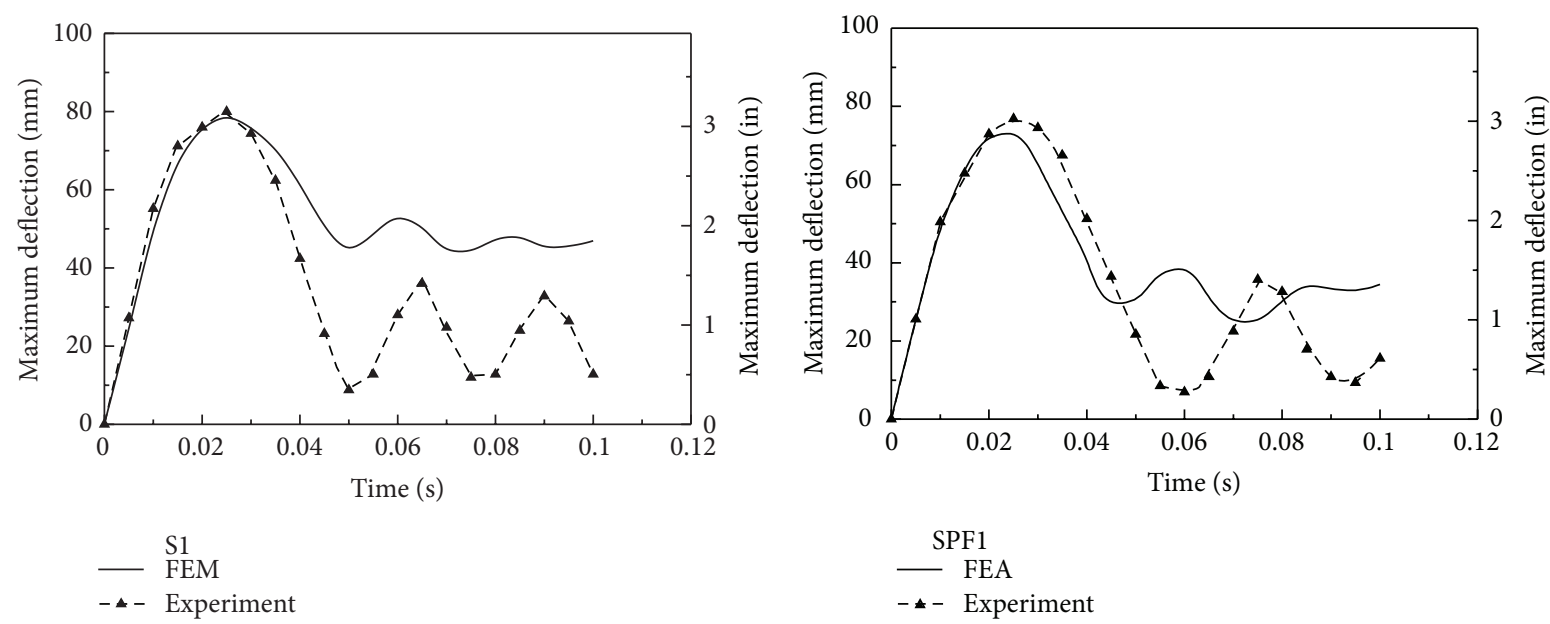

(a)
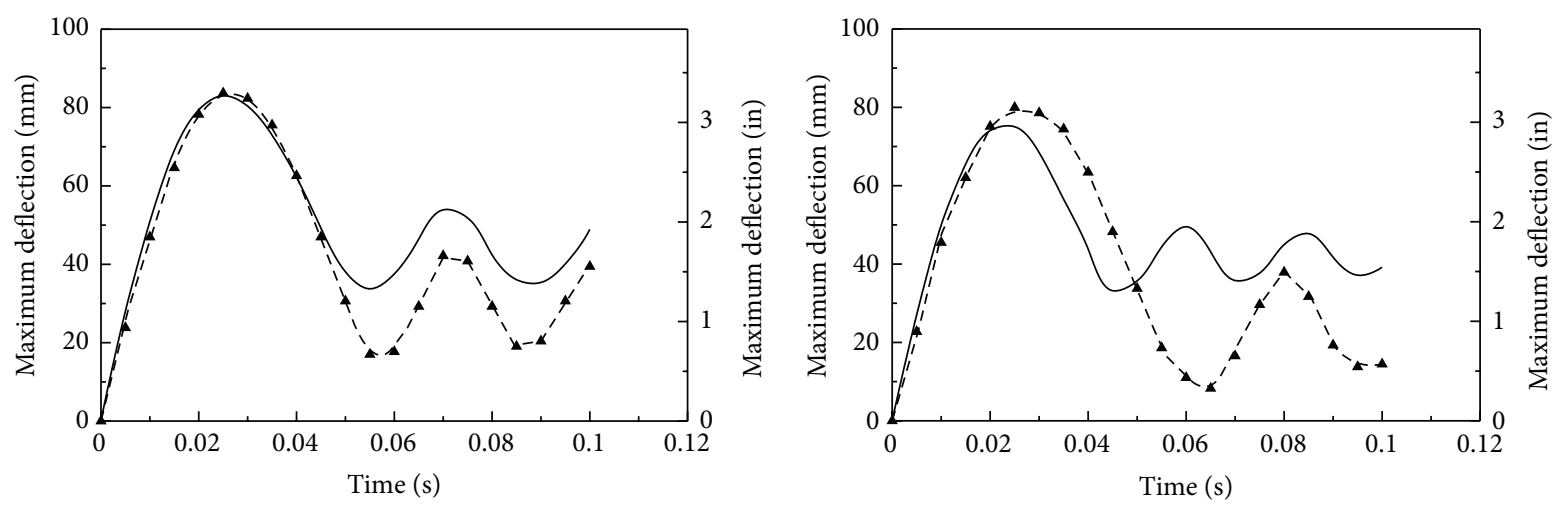

SPB1

SPF2

- - Experiment

(c)

(d)

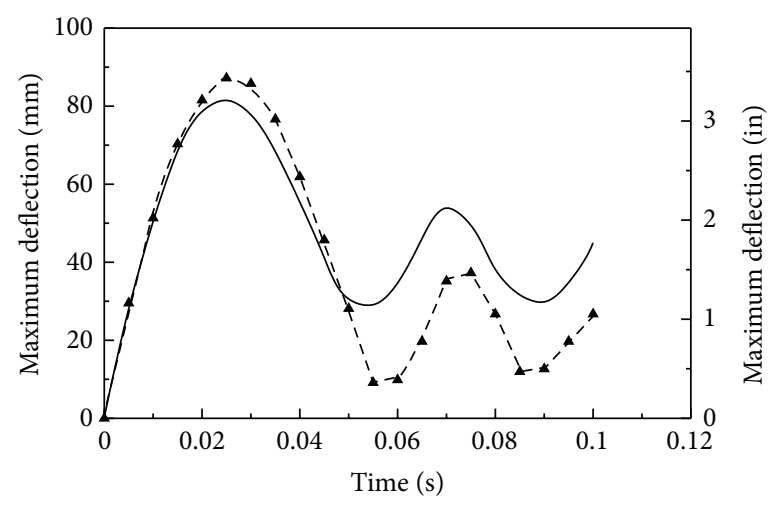

SPB2

- - Experiment

(e)

FIGURE 7: Displacement time-history comparisons. 


\section{Conclusions and Recommendations}

Based on results from the experimental and numerical investigations, the following conclusions can be drawn for the materials and specimens that were studied.

(1) The Johnson-Cook material model and the determined material constants were adequate for simulating the dynamic behavior of the AISI 4340 steel plate under the applied impact loading.

(2) The selected material model for polyurea, incorporating strain-rate-dependent test data, was able to account for strain-rate effects and simulate the dynamic behavior of the polyurea coated specimens under the applied impact loading.

(3) In many structural engineering applications, accurate predictions of maximum deformations, those that occur during the first peak of the observed dynamic response, are typically what is desired. The developed numerical model was able to accurately predict this peak response along with accurately mimicking the stiffness of the studied polyurea toughened steel plates under impact loading.

(4) The developed numerical model overestimated permanent plate deflections after the peak response. More impact tests are needed to better improve the accuracy of the model if predictions of postpeak behavior are desired.

\section{Conflict of Interests}

The authors declare that there is no conflict of interests regarding the publication of this paper.

\section{Acknowledgments}

This study was funded by US Office of Naval Research Grant no. ONR N00014-05-1-0844. The authors wish to thank Air Products and Chemicals, Inc., for providing polyurea and manufacturing the specimens used in this study.

\section{References}

[1] J. S. Davidson, J. R. Porter, R. J. Dinan, M. I. Hammons, and J. D. Connell, "Explosive testing of polymer retrofit masonry walls," Journal of Performance of Constructed Facilities, vol. 18, no. 2, pp. 100-106, 2004.

[2] M. S. Fatt Hoo, X. Quyang, and R. J. Dinan, "Blast response of walls retrofitted with elastomer coatings," in Proceedings of the 8th International Conference on Structures Under Shock and Impact, pp. 129-138, WIT Press, Crete, Greece, 2004.

[3] J. R. Porter, R. J. Dinan, M. I. Hammons, and K. J. Knox, "Polymer coatings increase blast resistance of existing and temporary structures," The AMPTIAC Quarterly, vol. 6, pp. 4752, 2002.

[4] M. A. Meyers, Dynamic Behaviour of Materials, John Wiley \& Sons, Hoboken, NJ, USA, 1994.

[5] G. R. Johnson and W. H. Cook, "A constitutive model and data for metals subjected to large strains, high strain rates, and high temperatures," in Proceedings for the Army Science Conference, Orlando, Fla, USA, 1983.

[6] T. Børvik, M. Langseth, O. S. Hopperstad, and K. A. Malo, "Ballistic penetration of steel plates," International Journal of Impact Engineering, vol. 22, no. 9-10, pp. 855-886, 1999.

[7] T. Borvik, O. S. Hopperstad, T. Berstad, and M. Langseth, "Perforation of $12 \mathrm{~mm}$ thick steel plates by $20 \mathrm{~mm}$ diameter projectiles with flat, hemispherical and conical noses, part II: numerical simulations," International Journal of Impact Engineering, vol. 27, no. 1, pp. 37-64, 2001.

[8] T. Børvik, A. H. Clausen, M. Eriksson, T. Berstad, O. Sture Hopperstad, and M. Langseth, "Experimental and numerical study on the perforation of AA6005-T6 panels," International Journal of Impact Engineering, vol. 32, no. 1-4, pp. 35-64, 2006.

[9] N. K. Gupta, M. A. Iqbal, and G. S. Sekhon, "Experimental and numerical studies on the behavior of thin aluminum plates subjected to impact by blunt- and hemispherical-nosed projectiles," International Journal of Impact Engineering, vol. 32, no. 12, pp. 1921-1944, 2006.

[10] I. M. Ward and D. W. Hadley, An Introduction to the Mechanical Properties of Solid Polymers, John Wiley \& Sons, New York, NY, USA, 1993.

[11] J. Yi, M. C. Boyce, G. F. Lee, and E. Balizer, "Large deformation rate-dependent stress-strain behavior of polyurea and polyurethanes," Polymer, vol. 47, no. 1, pp. 319-329, 2006.

[12] J. Shim and D. Mohr, "Using split Hopkinson pressure bars to perform large strain compression tests on polyurea at low, intermediate and high strain rates," International Journal of Impact Engineering, vol. 36, no. 9, pp. 1116-1127, 2009.

[13] C. M. Roland, J. N. Twigg, Y. Vu, and P. H. Mott, "High strain rate mechanical behavior of polyurea," Polymer, vol. 48, no. 2, pp. 574-578, 2007.

[14] LSTC, LS-Dyna 971, Livermore Software Technology Corporation, Livermore, Calif, USA, 2007.

[15] G. R. Johnson and W. H. Cook, "Fracture characteristics of three metals subjected to various strains, strain rates, temperatures and pressures," Engineering Fracture Mechanics, vol. 21, no. 1, pp. 31-48, 1985.

[16] D. L. Littlefield, C. E. Anderson Jr., Y. Partom, and S. J. Bless, "The penetration of steel targets finite in radial extent," International Journal of Impact Engineering, vol. 19, no. 1, pp. 4962, 1997.

[17] H. Kurtaran, M. Buyuk, and A. Eskandarian, "Design automation of a laminated armor for best impact performance using approximate optimization method," International Journal of Impact Engineering, vol. 29, no. 1-10, pp. 397-406, 2003.

[18] D. Fuentes, D. Littlefield, J. T. Oden, and S. Prudhomme, "Extensions of goal-oriented error estimation methods to simulations of highly-nonlinear response of shock-loaded elastomer-reinforced structures," Computer Methods in Applied Mechanics and Engineering, vol. 195, no. 37-40, pp. 4659-4680, 2006.

[19] LSTC, LS-DYNA Keyword User's Manual, Livermore, Calif, USA, 2007.

[20] C.-C. Chen, A study of blast effects on polyurea coated steel components [Doctoral Dissertation], The Pennsylvania State University, State College, Pa, USA, 2009. 

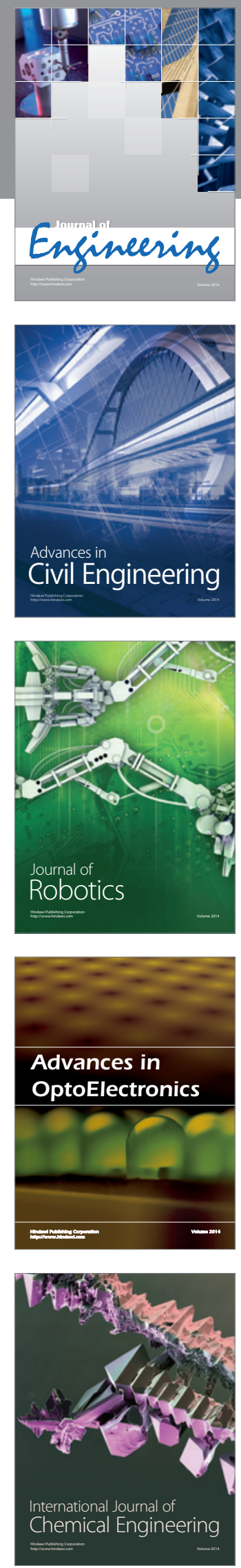

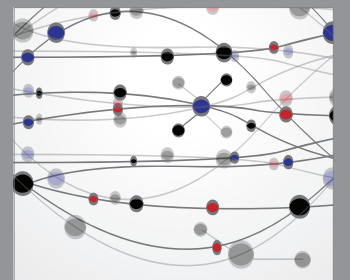

The Scientific World Journal
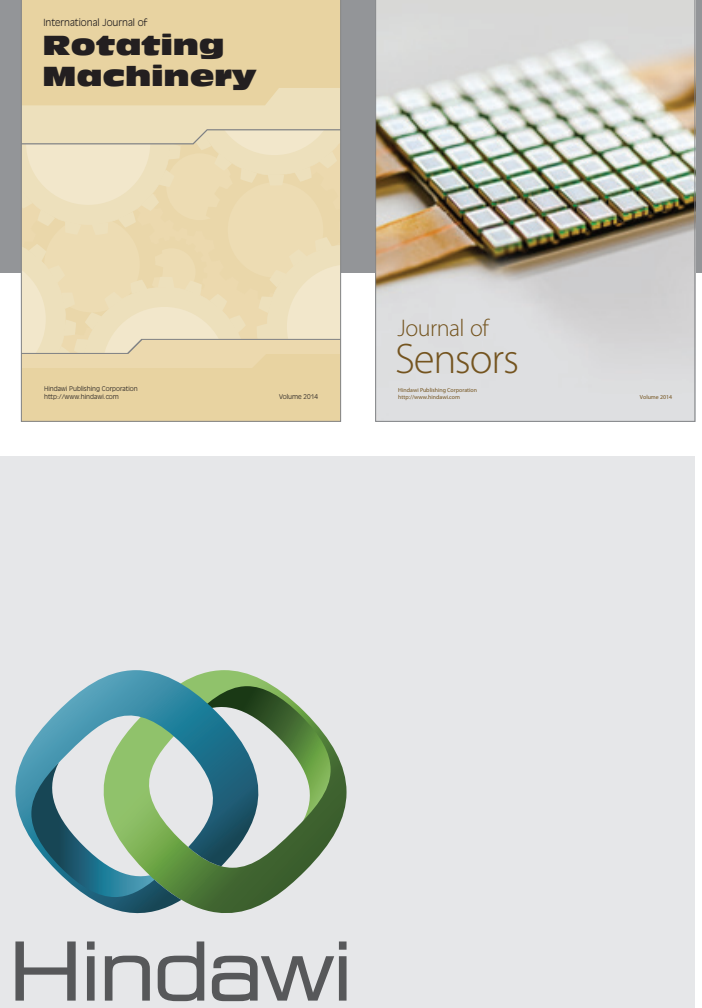

Submit your manuscripts at http://www.hindawi.com
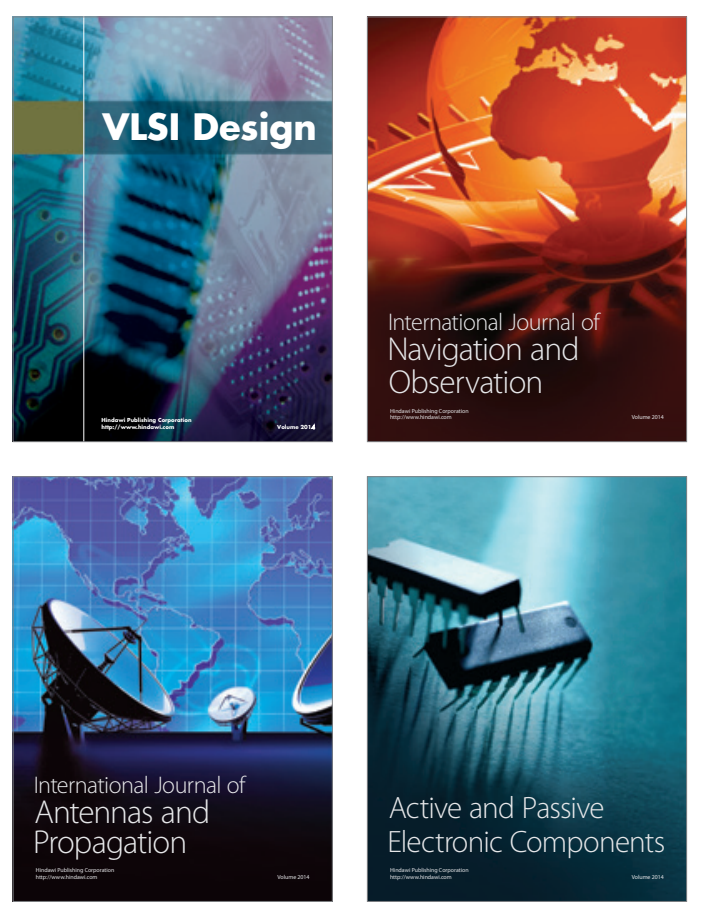
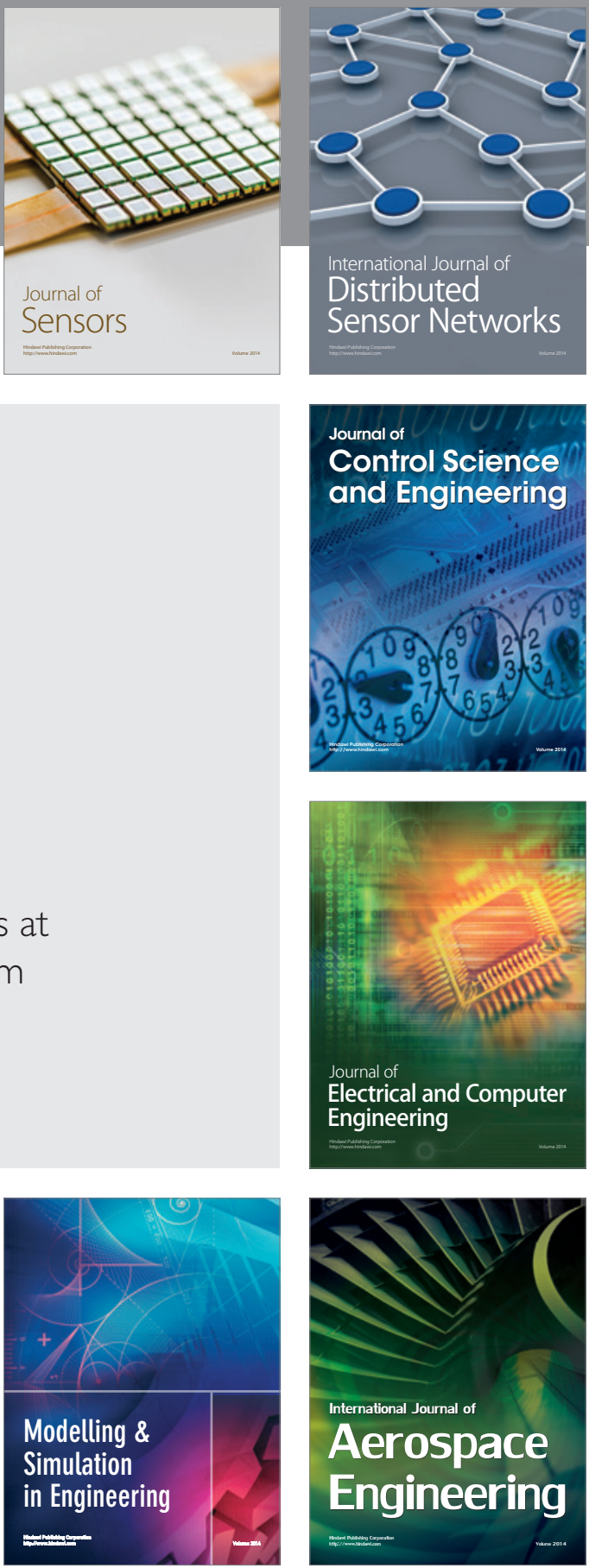

Journal of

Control Science

and Engineering
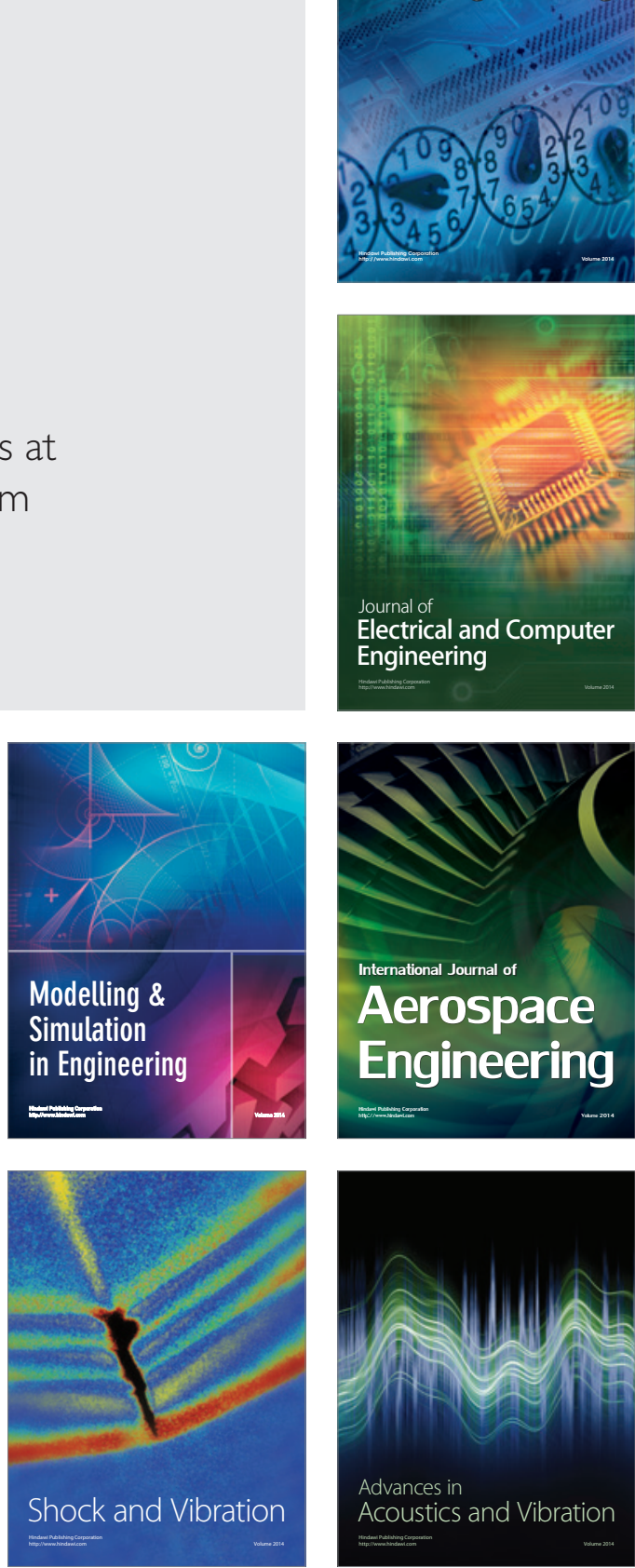